\title{
Comunicación corporativa, relaciones públicas y gestión del riesgo reputacional en tiempos del Covid-19
}

\section{Corporate communication, public relations and reputational risk management in the days of Covid-19}

\author{
Jordi Xifra
}

Cómo citar este artículo:

Xifra, Jordi (2020). “Comunicación corporativa, relaciones públicas y gestión del riesgo reputacional en tiempos del Covid-19". El profesional de la información, v. 29, n. 2, e290220.

https://doi.org/10.3145/epi.2020.mar.20

Artículo recibido el 14-04-2020 Aceptación definitiva: 20-04-2020

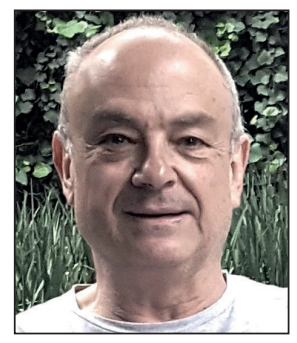

Jordi Xifra

https://orcid.org/0000-0001-7942-628X

Universitat Pompeu Fabra

Departament de Comunicació

Roc Boronat, 138. 08018 Barcelona, España

UPF Barcelona School of Management

Balmes, 132-134. 08008 Barcelona, España

jordi.xifra@upf.edu

\section{Resumen}

La crisis del Covid-19 ha puesto a prueba muchos procesos propios de las estructuras sociales. La comunicación corporativa y las relaciones públicas son ejemplos de estos procesos que se enfrentan a una situación inédita, difícilmente prevista y de la que habrá que sacar unas lecciones de cara al futuro. En este artículo, mezcla de investigación y ensayo, pretendemos, en base a la teoría, pero a partir de la experiencia y de algunos estudios llevados a cabo por profesionales de la comunicación, reflexionar sobre cómo afecta y condicionará la crisis de la pandemia del Covid-19 a la práctica de la comunicación corporativa en general, y de dos de sus áreas de especialización, la comunicación interna y la responsabilidad social corporativa (RSC). Hacemos hincapié en la importancia de que las organizaciones asuman que la reputación es un riesgo y que ese riesgo debe ser gestionado con las técnicas y herramientas propias de las relaciones públicas, pues si algo ha puesto de manifiesto la crisis de la pandemia del llamado coronavirus ha sido la importancia para las organizaciones y marcas de la gestión de unas relaciones de confianza con sus públicos.

\section{Palabras clave}

Covid-19; Coronavirus; Pandemias; Comunicación corporativa; Comunicación organizacional; Comunicación de crisis; Comunicación interna; Relaciones públicas; Responsabilidad social corporativa; RSC; Riesgo reputacional.

\begin{abstract}
The Covid-19 crisis has put to the test many social structures processes. Corporate communication and public relations are examples of these processes that face an unprecedented situation, difficult to foresee and from which lessons will have to be drawn for the future. In this article, a mixture of research and essay, we intend, based on theory, and on the experience and some studies carried out by communication professionals as well, to reflect on how the pandemic crisis of the Covid-19 affects and will condition the practice of corporate communication in general and two of its areas of specialization, internal communication and corporate social responsibility (CSR). We emphasize the importance of organizations in assuming that reputation is a risk and that this risk must be managed with public relations tactics and tools, because the pandemic crisis of the so-called coronavirus has revealed the importance for organizations and brands of managing trustworthy relationships with their publics.
\end{abstract}

\section{Keywords}

Covid-19; Coronavirus; Pandemics; Corporate communication; Organizational communication; Crisis communication; Internal communication; Public relations; Corporate social responsibility; CSR; Reputational risk. 


\section{Introducción}

Son muchos los interrogantes que la crisis pandémica del Covid-19 genera en el campo de la comunicación de las organizaciones. Sin ir más lejos: ¿Cómo interpretar desde un punto de vista académico la comunicación organizacional y la comunicación de crisis de gobiernos, empresas, ONGs en tiempos del coronavirus? ¿Cuál es el papel de las relaciones públicas y la comunicación estratégica en esta pandemia? ¿Qué cuestiones plantea desde un punto de vista teórico? ¿Qué prácticas se pueden recomendar y cuáles rechazar deontológicamente? ¿Cómo cubren o interpretan los medios y los expertos esta crisis? ¿Qué utilidad pueden tener las teorías para una buena práctica profesional en estos momentos? ¿Qué papel juegan las asociaciones profesionales de comunicadores? ¿Cómo influye y modifica la situación laboral de los profesionales y expertos en comunicación? ¿Cómo está afectando la crisis a la investigación y enseñanza de las relaciones públicas y la publicidad? ¿Hasta qué punto esta pandemia transformará nuestro campo de estudio?...

Está claro que la situación es lo suficientemente reciente como para poder tener la perspectiva necesaria para responder a todas estas preguntas. Pero no es menos cierto que ya se han realizado investigaciones, muy primarias, por parte del sector profesional de la comunicación estratégica y las relaciones públicas que pueden darnos pistas de por dónde irán las respuestas a los interrogantes planteados. Estos estudios y las reflexiones personales a partir de las experiencias conocidas y vividas se conjugan en las siguientes líneas, centrando el terreno de juego en los ámbitos estratégicos más directamente afectados por la crisis del Covid-19, la comunicación interna y la responsabilidad social corporativa (RSC), ámbitos que se inscriben profesionalmente en el marco de la comunicación de crisis y gestión del riesgo reputacional.

\section{Comunicación de crisis y gestión del riesgo reputacional: marco teórico e investigación profesional}

La reputación es un activo intangible crucial para cualquier organización. Son cada vez más las investigaciones sobre el tema que han identificado los elementos que constituyen la reputación corporativa. Sin ir más lejos, los resultados de las acciones pasadas de una organización (Weigelt; Camerer, 1988), los resultados de las experiencias directas e indirectas y la información recibida sobre una organización (Fombrun; Shanley, 1990; Yoon; Guffey; Kijewski, 1993; Fombrun; Gardberg; Sever, 2000), el grado en el que una organización es vista como responsable y confiable (Roberts; Dowling, 2002), o la eficiencia en la gestión de la comunicación interna (Miquel-Segarra; Aced-Toledano, 2019). A partir de sus diferentes elementos, Fombrun, Ponzi y Newburry (2015) definen la reputación corporativa como una representación colectiva del comportamiento y los resultados pasados de una organización que describe la capacidad que ésta tiene para ofrecer resultados estimables para sus públicos.

El concepto de reputación está ganando terreno a la hora de nominar contenidos propios de las relaciones públicas. Sin embargo, ya hemos apuntado en otro lugar (Xifra, 2017), que tanto la imagen como la reputación son difícilmente objeto de gestión (organizativa o individual), constituyendo un resultado final del comportamiento humano o corporativo. Intentar gestionar la reputación de uno mismo puede acabar convirtiéndose en la gestión de la popularidad de uno mismo, un esfuerzo que suele ser inoportuno, superficial y potencialmente frustrante. Los teóricos estadounidenses han demostrado que la gestión de la reputación no es precisamente el significado idóneo para describir la comunicación estratégica o las relaciones públicas, ya que carece de fundamento epistemológico e incluso práctico (Hutton et al., 2001).

\section{El concepto de reputación es inherente} al de comunicación

Con todo, la gestión de las relaciones públicas afectará directamente a la reputación, al ser ésta una consecuencia de dicha gestión. Así, el concepto de reputación es inherente al de comunicación. Incluso nos atrevemos a afirmar que la comunicación estratégica esconde otro tipo de gestión, la del riesgo reputacional (Xifra; Ordeix, 2009), concepto mucho más idóneo, pues mientras el riesgo es gestionable, no lo es la reputación, por los motivos aducidos unas líneas más arriba.

Esta idea de riesgo está directamente vinculada con la noción de crisis. Desde esta perspectiva, la selección de estrategias de comunicación debe basarse en situaciones de crisis tales como la tipología de la crisis y la gravedad del daño derivado. Coombs (2012) agrupa los tipos de crisis en tres conjuntos y los ordena en función de un nivel ascendente de responsabilidad:

- el grupo de las víctimas (por ejemplo, en un desastre natural),

- el grupo accidental (por ejemplo, en accidentes debidos a errores técnicos) y

- un grupo evitable (por ejemplo, accidentes por errores humanos).

El grupo de las víctimas produce escasa atribución de responsabilidad por la crisis, mientras que el grupo evitable produce la atribución más fuerte (Coombs, 2012), afectando de manera más notable a la reputación corporativa. Asimismo, la responsabilidad de la crisis también está influenciada por la gravedad del daño. Cuanto más daño causa una crisis, más responsabilidad se tiende a atribuir a la organización responsable (Coombs, 2006) y más daño causa a su reputación.

Dado que no todas las crisis responden a los mismos patrones de producción ni generan los mismos efectos, Coombs (2012) sugiere que las organizaciones deben identificar estrategias de comunicación de crisis que sean apropiadas para las diferentes situaciones críticas. A medida que el daño de una crisis a la reputación se intensifica, las percepciones de los públicos sobre la responsabilidad de la crisis se fortalecen junto con la necesidad de estrategias más acomodaticias (Coombs, 2012). Por consiguiente, si la responsabilidad de una organización en la crisis es baja, como ocurre con la 
crisis del Covid-19, las estrategias defensivas como la negación de responsabilidad o el traspaso de la responsabilidad a terceros pueden ser efectivas. De hecho, es lo que hizo Donald Trump en los meses iniciales de la pandemia, aunque veremos que una cosa es la crisis sanitaria global y otra distinta es la crisis económica y social derivada, que sí afecta a las corporaciones. Si la responsabilidad de crisis de una organización es alta por ejemplo, la gestión de las consecuencias que otra crisis mayor, como la del Covid-19, ha producido en la organización-, los públicos no esperan respuestas defensivas, sino las Ilamadas acomodaticias (Coombs, 1998), como una disculpa acompañada de acciones concretas. En función de cuál sea la estrategia reactiva elegida, la afectación a la reputación de la compañía será mayor o menor.

En el ámbito de la comunicación sanitaria hay que mencionar un trabajo que la pandemia que nos ocupa ha puesto de relevancia. En 2014, dos hospitales estadounidenses de Dallas, el Emory University Hospital y el Texas Health Presbyterian Hospital, se enfrentaron a los desafíos e incertidumbres asociados con el tratamiento de pacientes afectados por Ébola, con resultados muy dispares. El Emory trató con éxito a cuatro pacientes, mientras que el paciente del Texas Health fue diagnosticado erróneamente y murió, además de haber contagiado a dos enfermeras. Este caso de estudio sirvió a Woods (2016) para dirigir una investigación sobre cómo estas dos organizaciones hospitalarias planificaron y respondieron al riesgo de Ébola. Los resultados pusieron de manifiesto la necesidad de que, en casos de epidemias o pandemias como el Ébola, o ahora el Covid-19, monitoreen constantemente su entorno corporativo para abordar con prontitud cualquier riesgo potencial, en un esfuerzo por prevenir o aliviar una crisis de esta índole. Asimismo, esta investigación sugiere que los responsables de comunicación sanitaria, tanto del sector privado como del público, respondan rápidamente con información precisa y veraz para mantener la credibilidad, tranquilizar a los públicos y reducir la ansiedad sobre el riesgo para la salud, lo que incide claramente en la reputación de la organización.

La situación profesional derivada de la crisis del Covid-19 confirma estas teorías y evidencia la existencia todavía de una brecha entre la teoría y la práctica; brecha que deriva más de planteamientos alejados de la realidad en el campo de las relaciones públicas que de una ignorancia académica de lo que ocurre en el campo profesional (Xifra, 2017). Ahora bien, esto no excluye que, a pesar de ello, encontremos situaciones en los que la brecha entre lo normativo y lo que hay que hacer sea también fruto de una concepción de la comunicación estratégica menos ética profesionalmente y más ajustada a la idea de interés económico que a querer encontrar situaciones de comunicación bidireccional -eje de las relaciones públicas- entre las organizaciones y sus públicos.

El análisis de la reputación es uno de los campos donde mayor trabajo queda por hacer, especialmente académico. La mejor muestra es que este activo intangible es habitualmente monitorizado desde el sector profesional, siendo el académico incapaz de establecer modelos, especialmente cualitativos, para evaluar la reputación de una organización. Así, como corolario a lo que sucede en el área económica con las agencias de calificación de riesgos, en el terreno de las relaciones públicas encontramos agencias o consultoras que elaboran sus rankings reputacionales, pues la reputación es considerada parte esencial de los riesgos corporativos de toda empresa. El más conocido y respetado, tanto por su tradición como por la amplitud de la muestra y la metodología empleada, es el "Edelman trust barometer" de la agencia de relaciones públicas Edelman Worldwide, con implantación en prácticamente todos los países.

En abril de 2020, sólo tres semanas después de que una buena parte de los países europeos dictaran normas de confinamiento para su población en aras a evitar contagios que propagaran exponencialmente el virus, Edelman publicó un estudio exploratorio especial sobre los resultados de la investigación que llevó a cabo entre el 23 y el 26 de marzo de 2020 a través de Internet en doce países: Alemania, Brasil, Canadá, China, Corea del Sur, Estados Unidos, Francia, India, Italia, Japón, Reino Unido y Suráfrica. La muestra fue de 12.000 entrevistados, 1.000 por cada país (Edelman, 2020). Independientemente del rigor metodológico de la encuesta, menos estricto que sus barómetros anuales debido a la premura de tiempo en que querían comunicar los resultados, se trata de una investigación pionera
La crisis derivada de la propagación del Covid-19 no tiene precedentes, rompe con los modelos de gestión comunicativa de las crisis 
en la materia cuyos resultados deberán tener en cuenta en el futuro los directores de comunicación de todo tipo de empresas. Con todo, cualquier análisis académico de una situación de crisis corporativa no puede pasar por alto la teoría situacional de los públicos, de gran utilidad a la hora de planificar estrategias de respuesta en función del comportamiento de los públicos de una organización.

\section{La teoría situacional de los públicos y su utilidad en crisis globales}

La crisis derivada de la propagación del Covid-19 no es una crisis de las que Coombs $(1995 ; 1998 ; 2006 ; 2012)$ identifica claramente. Es una crisis sin precedentes. Es una situación que rompe con los modelos de gestión comunicativa de las crisis. Su responsable no tiene nombre y apellidos, más allá de las que el framing político quiera darle. Pero es una crisis que ha generado infinidad de crisis particulares y que ha derivado en una situación económica y social muy preocupante. Desde el ángulo de la gestión estratégica de la comunicación corporativa esta crisis afecta a diferentes públicos, pero principalmente a empleados, clientes y consumidores, lo cual conlleva un riesgo corporativo: pretender solucionar los problemas más con herramientas de marketing que de comunicación.

La crisis del Covid-19 debería poner en valor, ahora más que nunca, que los públicos son una cosa y los mercados son otra. En estas etapas iniciales de la pandemia, es el momento de los públicos; ya llegará el momento de los mercados. A finales del siglo pasado, James E. Grunig, el investigador más relevante de la corta historia de las relaciones públicas, estableció una clara distinción entre públicos y mercados a partir de su teoría situacional de los públicos de una organización (Grunig, 1976; 1983; Grunig; Hunt, 1984; Grunig; Repper, 1992).

Grunig investigó los factores cognitivos que determinan e identifican a los públicos, basándose en las definiciones de público de Dewey (2004) y Blumer (1946). Los niveles de comportamiento de los públicos respecto del problema u oportunidad que ha de ser objeto de la acción de relaciones públicas conforman el sustrato de la teoría situacional, en el sentido de que permite explicar cuándo y cómo se comunican los grupos y en qué casos la comunicación con los públicos será más eficaz.

Dewey (2004) definió un público como un grupo de individuos que se enfrenta a un problema similar, reconoce que el problema existe y se organiza para hacer algo acerca del problema. Para Blumer (1946), un público es un grupo de individuos que se enfrentan a un tema, están divididos en sus ideas respecto a cómo hacer frente al mismo y discuten sobre el tema. Con estos antecedentes, Grunig establece tres variables independientes que determinan cómo los miembros de los públicos perciben las situaciones del emisor que les afectan:

\section{1) Reconocimiento del problema}

Se fundamenta en dos variables dependientes: a) la búsqueda de información, es decir, los miembros de los públicos buscan información e intentan comprenderla (públicos informados o enterados), y b) el procesamiento de la información que, en oposición a la anterior, es una conducta pasiva de comunicación por cuanto este público procesa la información que le llega al azar sin haberla buscado. En el caso que nos ocupa es evidente que el reconocimiento del problema existe para todos los públicos dada la magnitud de la crisis, la circulación de la información a través de las redes sociales y la sobreinformación a la que está expuesta la problemática de salud pública.

\section{2) Reconocimiento de las restricciones}

Representa el grado de reconocimiento por los miembros de un público de obstáculos físicos, sociales, económicos o políticos de una determinada situación que frenan la posibilidad de planificar su conducta. Por consiguiente, si se dan cuenta de que tienen pocas posibilidades de elección de una conducta en una situación dada, la información que les ayuda a construir, definir, seleccionar y confirmar un comportamiento tiene poco valor para ellos. El propio confinamiento es hoy en día una restricción física para poder actuar (por ejemplo, manifestarse masivamente, a pesar de que se han realizado algunas "manifestaciones" virtuales) como colectivo general, como ciudadanía. Otra cosa es cuando nos referimos a públicos más específicos e identificables como clientes o consumidores, incluso trabajadores, de una compañía. En este caso, la alta y prácticamente exclusiva prioridad de las cuestiones sanitarias y de salud pública, suponen en sí mismas un reconocimiento de las restricciones a la hora de actuar como tales públicos, pues sus pretensiones pueden verse eclipsadas y no tener la repercusión que debieran. Solo hay una excepción, la del colectivo del personal sanitario que en esta pandemia no tiene más restricciones que las éticas, es decir, dejar de lado cuestiones de seguridad en el trabajo y precariedad laboral y dedicarse a desempeñar su trabajo. Y aun así, en las semanas iniciales de la pandemia, ya vimos como representantes sindicales actuaron en nombre de este colectivo.

\section{3) Nivel de implicación cognitiva}

Es la variable que permite distinguir si la conducta comunicativa del público será activa o pasiva. Un miembro de un público con un alto nivel de implicación será normalmente una persona con un alto nivel de reconocimiento del problema y de poco reconocimiento de las restricciones. Es el ejemplo de los profesionales sanitarios en la crisis que nos 
ocupa, que no tuvieron más restricciones que las deontológicas. El grado de implicación (o compromiso) del público es proporcional a su activismo. Cuando los individuos se enfrentan a una situación, juzgan si sus propios intereses o los de terceros están afectados. Si así lo consideran, pueden examinar la situación y determinar si el problema existe. De lo dicho en relación con las dos primeras variables, la crisis del Covid-19 ofrece una nueva perspectiva, en el sentido que el nivel de implicación cognitiva existe, pero el activismo que de él deriva se diferirá en el tiempo. Es decir, además del ejemplo del personal sanitario, si como clientes hemos sido víctimas de cancelaciones de vuelos o anulaciones de reservas hoteleras, las primeras semanas de la expansión de la pandemia no son aquellas en las que pasaremos de ser miembros del mercado turístico a actuar como públicos activos. Esto podrá llevarse a cabo una vez la actividad económica y las organizaciones turísticas y de transporte cuya actuación nos ha afectado vuelvan a estar operativas.

La secuencia temporal de las variables es la siguiente: en primer lugar, se reconoce un problema; luego, se valoran sus posibles repercusiones personales, resultando un nivel de implicación con el problema; finalmente, dado que el problema existe y tiene consecuencias personales, se ha de decidir si puede hacérsele frente o no de alguna manera, protegiéndose o influenciándolo. En este último estadio juega un papel importante el reconocimiento de las restricciones. De ahí que la propia situación económica de parón económico es en sí un reconocimiento de las restricciones pero que no limita para siempre el grado de activismo del público, sino que, como en el caso del personal sanitario, lo aplaza. Esta es la novedad de esta crisis y de su afectación a una teoría clave para poder actuar ante una situación como esta.

Hay un público al que, aun así, cualquier aplazamiento secuencial de la teoría situacional difícilmente puede afectarle, porque es un público que sufre las consecuencias no solo de la pandemia, sino de las crisis derivadas, la económica y social. Nos referimos a los trabajadores. De ahí que la comunicación interna sea seguramente el escenario en el que los cambios son más profundos y requieren una acción estratégica más rápida y responsable de las organizaciones. A ella dedicamos los próximos apartados, no sin antes hacer hincapié en que la teoría situacional permite al profesional de las relaciones públicas elegir las técnicas más adecuadas para influir en las actitudes y comportamientos de sus públicos, de acuerdo con los objetivos perseguidos. Así, en la crisis del Covid-19, la línea argumental primordial ha sido la de quedarse en casa confinados, que se ha traducido en el eslogan "Quédate en casa". Para conseguir este comportamiento en la población, en el caso de España, los gobiernos del estado y de las comunidades autónomas han gestionado la comunicación pública para que la población en general se convierta en un público activo, en el sentido de que cumpla con quedarse confinado el tiempo que requiera la solución sanitaria de la crisis. Es decir, un público con alto reconocimiento del problema y bajo reconocimiento de las restricciones, aunque en este caso por imperativo del estado de alarma.

Ahora bien, ¿qué utilidad puede tener la teoría situacional para investigar la comunicación corporativa de las empresas durante la crisis del Covid-19? Como indicábamos más arriba, permite identificar públicos y diferenciarlos de mercados. En situaciones de crisis, los mercados pueden convertirse en públicos. Eso ocurre en crisis alimentarias por culpa de una determinada marca, donde los consumidores se convierten en públicos activos, que reconocen el problema y tienen un alto grado de implicación, incluso reconociendo ciertas restricciones. Así sucedió en el verano de 2019 con el brote de listeriosis registrado a cuenta de la carne mechada de la marca sevillana Magrudis. Los afectados se convirtieron en un público, siguiendo la definición de Dewey (2004), algunos de ellos, además, en un público activo. En ese momento, las herramientas de marketing no sirvieron, solo las de comunicación.

El 14 de abril de 2020, un tribunal de Nanterre (Francia) dio a Amazon France un plazo de 24 horas para restringir sus envíos de productos básicos como la alimentación, con el aviso de una posible multa de un millón de euros por cada día de retraso y cada infracción, hasta que no hiciera una evaluación completa de los riesgos sanitarios para sus trabajadores. Este fallo, tomado a partir de un recurso presentado por los sindicatos, que dudaban de las condiciones de protección de los trabajadores de la compañía, ha hecho aflorar de nuevo la cuestión de la protección de Amazon a sus trabajadores durante la pandemia. No sabemos todavía cuáles serán las consecuencias, pero si afecta a sus ventas, estaremos ante una situación como la descrita, donde el mercado se puede convertir en un público activo que boicotee su actividad.

Asimismo, el caso tiene una vertiente más relevante. A raíz de la sentencia, Amazon cerró sus instalaciones una semana, manteniendo los salarios de todos los trabajadores afectados. Esta decisión salarial, que objetivamente es positiva, no tuvo un efecto balsámico entre los sindicatos, que declararon que no era una cuestión salarial, sino sanitaria y de 
seguridad en el trabajo. Es decir, las decisiones económicamente beneficiosas no funcionan en estos casos. De la misma manera que cuando hay una crisis derivada de un producto o servicios, los públicos suelen exigir información y no quieren rebajas en el precio o servicios gratuitos, a los trabajadores, en situaciones de crisis sanitarias, prefieren soluciones sanitarias más que salariales. Pasan de ser un "mercado interno" por seguir con el símil mercadotécnico, a públicos internos activos.

En definitiva, durante una pandemia como la que nos ocupa, no es el momento de vender, sino de informar y ofrecer soluciones, y las marcas deben centrar todos los esfuerzos en encontrar soluciones apropiadas y significativas para los problemas que enfrentan los públicos afectados directa o indirectamente por el Covid-19. EI principal afectado es, a ciencia cierta, el público interno.

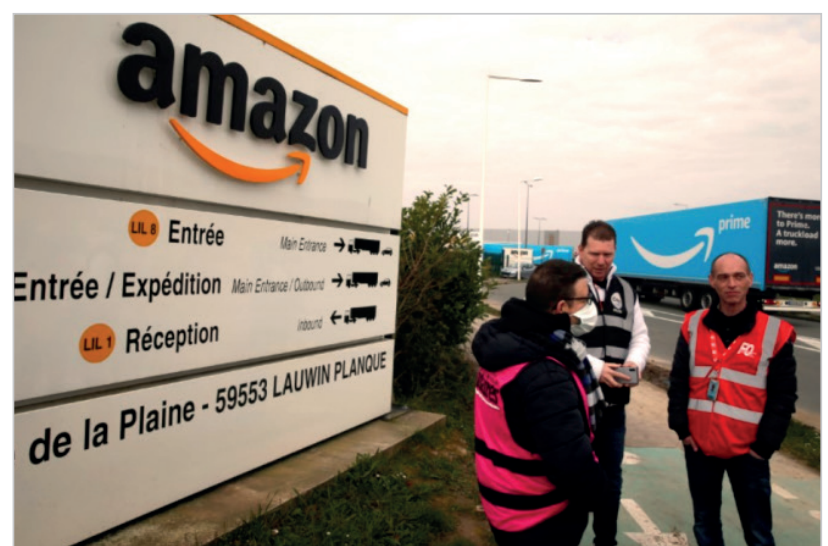

Figura 3. Amazon suspende la distribución en Francia tras un fallo judicial. https://www.fr24news.com/fr/a/2020/04/amazon-suspend-sadistribution-en-france-apres-une-decision-de-justice.html

\section{Impacto de la crisis del Covid-19 sobre la comunicación interna}

En su estudio sobre la evaluación de resultados de la comunicación interna en las organizaciones, Miquel-Segarra y Aced-Toledano (2019) concluyen que se trata de una cuestión que despierta un interés mayor en las empresas, aunque no es considerada una prioridad. Aunque su investigación se centró en la fase evaluativa del proceso estratégico, el carácter crítico de esta fase (Xifra, 2017) permite extender la valoración a el proceso de comunicación interna en general, por lo que los resultados confirman la tendencia de que la comunicación interna no es una actividad que ocupe los principales puestos del ranking de actividades de comunicación llevadas a cabo por organizaciones o agencias de relaciones públicas (O’Neil et al., 2018; Zerfass et al., 2018).

La crisis sanitaria del Covid-19 es una de esas crisis no evitables que difícilmente afectan por sí mismas a la reputación de las organizaciones (Coombs, 2012), pero, en cambio, puede generar crisis de confianza si no se actúa cumpliendo las expectativas de los públicos (Laurent, 2019). En este caso, la deriva económica y social de la crisis afectará directamente a la reputación corporativa en función de cómo se actúe en cuestiones de comunicación interna. En la investigación de Edelman (2020), los encuestados reconocieron la necesidad de una acción corporativa específica para ayudar a abordar los desafíos sociales planteados por el Covid-19, en especial para proteger el bienestar y la seguridad de los empleados. En esta línea, el $72 \%$ de los encuestados afirmó que su país no superará esta crisis sin que las organizaciones jueguen un papel fundamental para abordar los desafíos económicos y sociales derivados de la pandemia. Es decir, la opinión pública exige un compromiso social a las empresas, cuestión que está ligada a la responsabilidad social corporativa (RSC) y que permite establecer un vínculo que la teoría de la comunicación estratégica y las relaciones públicas no había realizado: la gestión de la comunicación interna pasa a ser también una cuestión de RSC.

\section{La gestión de la comunicación interna pasa a ser también una cuestión de res- ponsabilidad social corporativa}

Esta idea viene reforzada por las respuestas a la afirmación de que las compañías deben hacer todo lo posible para proteger el bienestar y la seguridad económica de sus empleados incluso si eso significa sufrir grandes pérdidas financieras hasta que termine la pandemia. El 52\% de los encuestados considera que las marcas deben hacer esto para mantener o aumentar su confianza y por ende su reputación; mientras que el 38\% espera que lo hagan, aunque no lo consideran una obligación. Por consiguiente, únicamente un $10 \%$ considera que la cuestión laboral no es una problemática que deban resolver las organizaciones.

La comunicación interna no ha tenido la misma consideración estratégica que otros tipos de comunicación, como las relaciones con los medios. Ha sido siempre la gran olvidada (Hamori, 2003; Xifra, 2017), por lo que se hace difícil poder conjugar la protección del bienestar de los trabajadores con la supervivencia económica. La crisis del Covid-19 ha puesto de manifiesto lo que la teoría crítica de las relaciones públicas defiende a partir de la investigación de las prácticas profesionales en cualquier situación, ya sean tiempos de bonanza o de crisis: las relaciones entre las organizaciones y sus públicos son relaciones de poder en las que el mantenimiento de la hegemonía en la relación es la finalidad de las empresas o compañías responsables de las estrategias comunicativas (Edwards, 2006; 2014).

Por este motivo, las organizaciones deben seguir algunos principios y reglas básicas en su gestión de la comunicación interna. En primer lugar, se trata de que la compañía sea una fuente de información veraz y completa para sus empleados. No basta con enviar abrazos virtuales o que el director general, el gerente o el rector de la universidad envíen pautadamente unos mensajes ad hoc que lo único que hacen es dar la impresión de un deber cumplido más que de una preocupación real por lo que sucede con la situación laboral de sus empleados. Se trata de informar de aquello que sea del interés de los públicos internos afectados por la crisis, y no de informar de lo que interesa y conviene a los líderes corporativos. 
Los procesos de comunicación interna son específicos de cada tipo de organización. Hay organizaciones singulares en las que estas situaciones de crisis exigen una gestión mucho más profunda de la comunicación. El problema es que normalmente son organizaciones cerradas y burocráticas poco acostumbradas a la gestión de la comunicación interna, como ocurre, por ejemplo, con las universidades públicas. Por una parte, no son las principales promotoras de expedientes de regulación temporal de empleo (ERTE), ya sea porque su personal es en gran parte o mayoritariamente funcionario y porque su actividad se ha adaptado a la modalidad de teletrabajo. Ateniéndonos a nuestra experiencia como personal docente e investigador de una universidad, hemos constatado como los mensajes de los que hemos sido destinatarios no han cumplido con esta función de información general. Han sido mensajes programados temporalmente (uno por semana), de apoyo, algunos con un alambicado lenguaje más dirigido al personal docente que al resto de público interno. No ha habido mensajes o aportaciones de científicos o investigadores especialistas en la materia. Esta ausencia de comunicación experta, si ya es grave en el sector privado, más lo es en el sector universitario. En la encuesta de Edelman (2020), un 84\% de las respuestas considera que ser una fuente fiable de información, mantener a las personas informadas sobre el virus y los progresos realizados en la lucha contra él, será una garantía de mantenimiento o mejora de la reputación, aunque el $42 \%$ espera que se haga, aunque es consciente de que no es una obligación corporativa. Cierto es que habría que matizar en función del sector de la compañía, pues no es lo mismo una empresa aseguradora que una empresa farmacéutica, pues esta última puede actuar como fuente de información científica de interés general.

Por eso es importante identificar a todos los públicos internos y los medios de comunicación de la organización más eficaces para relacionarse con ellos. No hay que olvidar a ningún colectivo. Ahora bien, en momentos de incertidumbre es más necesario que nunca priorizar la comunicación directa, aunque sea por vías telemáticas, desde cargos intermedios y sus equipos hacia abajo, y de los equipos entre ellos. Hay que asegurarse que las herramientas digitales son las adecuadas para esta comunicación fluida y que los líderes entienden su rol como facilitadores de las conversaciones y el compromiso. De esta manera, en situaciones como la generada por el Covid-19, deben sentir, literalmente, que la empresa vela por su bienestar y le ofrece cierta seguridad en tiempos de crisis. Las decisiones tácticas o no empáticas afectarán negativamente a la reputación corporativa. La gestión del riesgo reputacional pasa más que nunca, en estas situaciones, por una gestión transparente y directa de las relaciones con los trabajadores. Las tecnologías de la información se han convertido en el mejor aliado para

Las decisiones tácticas o no empáticas afectarán negativamente a la reputación corporativa este cometido.

\section{Explosión de nuevas técnicas de comunicación interna}

La crisis social del Covid-19 afecta también a los medios y técnicas de comunicación interna. El cambio de modelo laboral, con el paso a modalidades de teletrabajo de funciones que nunca se plantearon un uso exclusivo de las tecnologías de la información como canal prioritario de comunicación entre empleadores y empleados, es uno de los rasgos fundamentales de esta crisis. Así, esta situación ha permitido en algunos casos optimizar técnicas y herramientas existentes y, en otros, trasladarlas al entorno laboral cuando su utilización estaba reservada principalmente a las relaciones interpersonales y sociales, sin rupturas ni disfunciones en la actividad laboral.

Esta transformación en la utilización de los medios de comunicación interna se concreta en el uso de tecnologías en la nube, en particular en la modalidad SaaS (software as a service), como estrategia para aprovechar las ventajas que ofrecen las soluciones cloud, para dedicar los esfuerzos y los recursos propios a aquellas actividades tecnológicas e informáticas que aportan valor añadido a la organización y que permiten, en consecuencia, seguir desarrollando los proyectos existentes antes de la crisis, poner en marcha nuevos y, muy especialmente, mejorar la atención a los usuarios. Uno de los sectores que más rápidamente ha tenido que adaptarse ha sido el educativo, tanto escolar como universitario. En este punto, el SaaS ha permitido potenciar las plataformas de enseñanza en línea.

Otro elemento de esta transformación es el uso de tecnologías orientadas a facilitar la movilidad TIC de los usuarios, en el sentido de que los datos y las aplicaciones van con los usuarios allí donde ellos vayan. Algunas organizaciones han promovido modelos para facilitar el acceso a sus sistemas de información desde cualquier lugar y en cualquier momento. Estos procesos se concretan en la implementación de plataformas de aplicaciones virtualizadas (MyApps), que permiten a cualquier empleado utilizar las aplicaciones desde cualquier dispositivo, lugar y momento para trabajar desde el hogar sin necesidad de desplazarse al lugar de trabajo. También permite a los cuadros intermedios trabajar con las aplicaciones de forma remota, así como el acceso a la suite de Google facilitando el trabajo a distancia con aplicaciones como Gmail, Google Drive, Google Docs, Google Apps, Hangouts Meet, Chat, Grupos, etc.; y el uso de herramientas de mensajería y trabajo en grupo, como Slack. Asimismo, en el ámbito de las administraciones públicas se han promovido modelos de certificados electrónicos y dispositivos de lectura de tarjetas chip para que, aquellas personas que, por las competencias propias de su puesto de trabajo, necesitan realizar firma electrónica, puedan hacerlo desde cualquier lugar.

Finalmente, no hay que olvidar que es fundamental que los canales de comunicación interna tengan garantizado su funcionamiento, por lo que esta nueva situación derivada de la pandemia abre una nueva función en la comunicación interna corporativa, la de la gestión de las infraestructuras de última generación de las redes físicas e inalámbricas para dar respuesta, rápida, sólida y segura, al aumento de comunicaciones que se produce para poder acceder a los 
recursos y servicios en la nube. Está claro que cuando la tecnología no es residente sino remota este asunto adquiere una gran importancia y tiene que formar parte de la agenda de los responsables de comunicación interna de las organizaciones.

Ahora bien, disponer de una red resistente a los flujos de transmisión de datos es tan fundamental como fomentar el control de la comunicación entre los empleados. Así lo han sugerido recientemente Kim y Pilny (2019) y Ter-Hoeven y Van-Zoonen (2020) que, después de concluir que la comunicación interna se erosiona a partir de ejercer el teletraba-

jo más de dos días y medio a la semana, el control de la comunicación, en cambio, puede rebajar este deterioro. En consecuencia, las organizaciones pueden fomentar el uso de las TIC por los empleados de varias maneras, como, por ejemplo, proporcionando dispositivos y otros soportes, como demostró en su día Mazmanian (2013). Sin embargo, dado que la mayoría de los empleados actualmente usan dispositivos tecnológicos para el trabajo, podría ser más beneficioso si las organizaciones intentan establecer normas que promuevan recorridos heterogéneos del uso de las tecnologías, proporcionando a los empleados el control sobre sus patrones de uso (Ter-Hoeven; Van-Zoonen, 2020).

Así, pues, la crisis del Covid-19 tiene una clara implicación en los procesos de comunicación interna, en el aumento del uso de aquellas técnicas virtuales que se utilizaban normalmente, y en la expansión de otras que no formaban parte de las relaciones entre empleados o con los empleados. Todavía es pronto para evaluar la efectividad de la aparición de usos de nuevos medios de comunicación interna, pero todo parece indicar que estas técnicas, como el virus, han llegado, como se dice popularmente, para quedarse y alterar los modelos laborales tradicionales.

\section{Liderazgo corporativo y comunicación interna: las claves de la crisis organizacional}

Si partimos de la base de que una empresa es una suma de personas que persiguen un fin común, es obvio que esas personas que la forman pueden ser sus mejores embajadoras (Arthur W. Page Society, 2017; Luc Beauregard Centre of Excellence in Communications Research, 2017; Men; Yue, 2019).

En realidad, son los trabajadores quienes materializan la identidad de una organización a través de su comportamiento y su actitud. Puesto que esto tiene un impacto directo en las percepciones y las opiniones del resto de públicos, está claro que los empleados ayudan a construir la reputación corporativa de la empresa.

Los empleados influyen de forma decisiva en la reputación corporativa a través de la imagen de la organización que proyectan en sus círculos de influencia (Schaarschmidt; Walsh; Ivens, 2015). Cada vez que hablan de la empresa en redes sociales o interactuando en persona con los públicos externos, los trabajadores están contribuyendo a la construcción y reafirmación de la reputación de la organización. Por eso, podemos decir que la gestión de la reputación es en realidad la gestión de personas, pues la reputación interna está estrechamente vinculada con la gestión de recursos humanos y la voz de los empleados (Wæraas; Dahle, 2019).

Además, los trabajadores generan mayor confianza en el resto de los públicos que la organización para la que trabajan (Corporate Excellence; IE Business School, 2016; Edelman, 2019; Men, 2014), superior incluso a la generada por los altos directivos, aunque el líder corporativo tenga un peso importante en la reputación de la empresa que lidera (Sotillo, 2017). Según el estudio "Company behind the Brand: CEO Spotlight" (Weber Shandwick, 2012), el 49\% de la reputación corporativa es atribuible al líder corporativo.

El liderazgo basado en la autenticidad contribuye en gran medida a la percepción positiva de los empleados sobre la organización e influye en la formación de una buena reputación interna, que a su vez se traduce en una reputación externa positiva, puesto que la reputación se construye de adentro hacia afuera de la empresa (Men, 2014). La reputación del líder corporativo es crítica en la generación de confianza de la organización y actúa como aval en momentos de crisis o de cambio (Edelman, 2019; Sotillo, 2017). 
En su investigación sobre el liderazgo en las corporaciones estadounidenses, Yue et al. (2019) concluyen que el liderazgo y la comunicación son factores clave para generar y reforzar la confianza de los empleados, lo que favorece su aceptación e incluso colaboración en procesos de cambio. Estos procesos a menudo se relacionan con crisis empresariales derivadas de alteraciones en el entorno económico del sector de actividad o del país de operatividad. La situación provocada por el Covid-19 es nueva y va a tener que redefinir la función del liderazgo corporativo en estas situaciones.

Así lo demuestra una investigación llevada a cabo por la agencia de comunicación estadounidense Orangefiery entre el 25 y el 29 de marzo de 2020 entre 127 líderes empresariales y 327 trabajadores de diferentes tipos de organizaciones (Orangefiery, 2020). Lo primero que hay que destacar de sus resultados es que el $83 \%$ de las organizaciones norteamericanas se han visto afectadas por la crisis de la pandemia del Covid-19. La investigación muestra que los líderes empresariales se han enfrentado al desafío de comunicarse con los empleados durante la pandemia, pero solo una escasa mayoría de los empleados dicen estar muy satisfechos con las comunicaciones que han recibido.

\section{COVID-19 leadership best practices}

BEHAVIORS AND PRACTICES

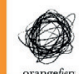

Figura 5. Orangefiery ha sido una de las consultoras que antes ha analizado el impacto en el liderazgo y la comunicación interna en el entorno del Covid-19.

https://pbs.twimg.com/media/EUESbgAWoAMKtBm.jpg

Al evaluar los mensajes que han recibido los empleados sobre el Covid-19 de parte de sus empleadores, el $82 \%$ ha recibido información sobre el tema. De este porcentaje, el $85 \%$ considera que se han utilizado los canales adecuados y el 79\% que la frecuencia es también la adecuada.

Sin embargo, los porcentajes disminuyen cuando se trata de la confiabilidad de los mensajes, lo cual es clave en la gestión de la reputación. Así, aunque la mayoría dice que las informaciones recibidas eran "muy" o "extremadamente" confiables (66\%), apropiadas en el tono (66\%), claras (64\%) y honestas y abiertas (63\%), los porcentajes disminuyen entre quienes responden que están muy o extremadamente satisfechos con los mensajes que están recibiendo (55\%) y solo el 53\% afirma que los mensajes son muy o extremadamente útiles para comunicar cómo deberían actuar los empleados.

Por su parte, los líderes corporativos califican mejor la gestión de la comunicación interna. Así, la mayoría afirma que la información es muy o extremadamente confiable (75\%), clara (69\%), honesta y abierta (75\%), eficaz para aliviar la ansiedad y la preocupación (66\%) y útil para comunicar cómo los empleados deberían actuar (58\%). Asimismo, un porcentaje mayor de ejecutivos empresariales considera que la comunicación era lo suficientemente frecuente $(85 \%$ frente al $79 \%$ de los empleados). Existe, pues, una brecha entre la consideración de uno y otro colectivo, aunque es menor de la que puede producirse en situaciones de normalidad en relación con problemáticas más concretas o crisis locales como expedientes de regulación de empleo, fusiones empresariales (McKie; Lawniczak, 2009) u otras situaciones que afectan la relación laboral de los trabajadores, incluso los sanitarios (Lee; Li, 2020).

Además, la brecha también afecta a la idea de compromiso organizativo con la gestión de la crisis. Así, una escasa mayoría (54\%) de los empleados cree que su organización está muy comprometida con la satisfacción de sus necesidades de comunicación, frente al $64 \%$ de los ejecutivos que opina lo mismo. Menos de la mitad de los empleados (43\% frente al $60 \%$ de los líderes) considera que su organización está muy o extremadamente interesada en escuchar los comentarios de los empleados durante esta pandemia.

A la hora de analizar los cambios que van a producirse en el futuro, el estudio de Orangefiery (2020) es, a día de hoy, clave. En más de 200 respuestas abiertas a una pregunta sobre qué deberá cambiarse en el futuro como consecuencia de la pandemia, los empleados afirman que quieren saber cuál será el impacto de la interrupción de la actividad en su puesto de trabajo de cara al futuro, al tiempo que reclaman información más frecuente y directa de los principales líderes corporativos. Orangefiery (2020) va más allá y también centra su investigación cuantitativa en las expectativas de trabajadores y directivos sobre qué cambios deben producirse en la gestión de la comunicación interna en situaciones de crisis como la que nos ocupa. Los resultados son los siguientes:

- Transparencia sobre lo que la organización sabe y no sabe (32\%).

- Más información sobre recursos para la salud mental y emocional, incluida la gestión del estrés y la ansiedad (25\%).

- Mayor reconocimiento de la dificultad de la situación (23\%).

- Más frecuencia en los mensajes (22\%).

- Más claridad en la información (22\%).

- Mayor reconocimiento directo de las fake news (22\%).

- Más información sobre los derechos de los trabajadores para poder tratar con familiares enfermos, estar al cuidado de hijos y otros familiares, y otros deberes derivados de la conciliación con la situación familiar (21\%). 
Con relación a aquellos principios de la comunicación interna eficaz que los líderes corporativos consideran clave en situaciones como la generada por el Covid-19, las cinco principales categorías son:

- honestidad y transparencia;

- mantenimiento de la calma;

- guiar a los empleados con el ejemplo;

- ayudar a los empleados en su seguridad y salud;

- comunicar con mensajes claros y directos.

Es muy significativa una de las repuestas de un líder corporativo de una compañía importante: "Sólo hay que ser abierto y transparente con los empleados. Estos son tiempos de miedo".

En definitiva, en tiempos de miedo como los del Covid-19, el liderazgo corporativo debe gestionar la comunicación interna con transparencia, con la máxima claridad posible, con calma y con empatía. Estos comportamientos, junto con demostrar la máxima apertura al diálogo con los empleados y aclarar cómo se ve el futuro, son las principales prioridades para construir reputación corporativa entre los públicos internos. Por todo ello, los profesionales de las relaciones públicas deben centrarse en gestionar medidas de contingencia a corto y medio plazo para afrontar la crisis, como las investigadas por UK PR Industry (2020), entre responsables de relaciones públicas británicos.

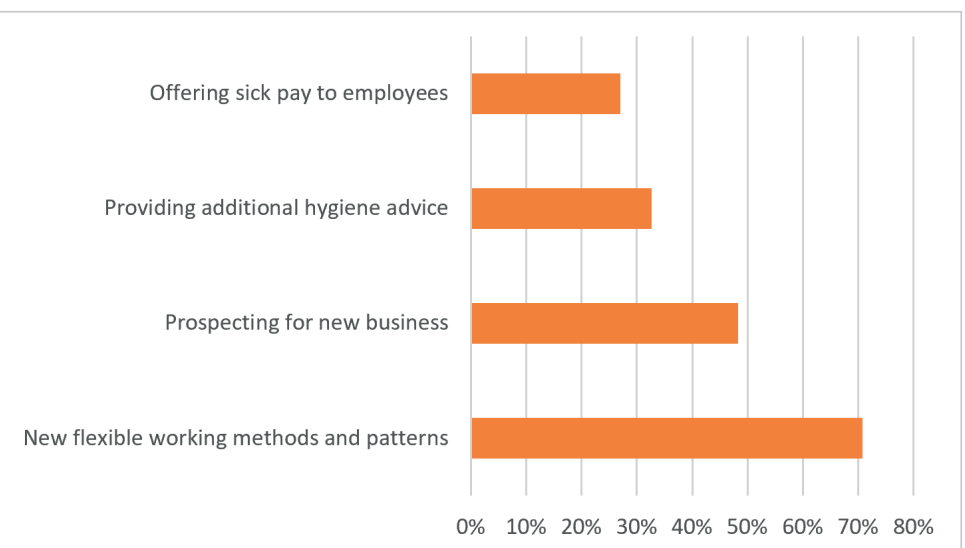

Figura 6. Medidas de contingencia a corto plazo que deben tomar las empresas para afrontar la crisis, priorizadas de menor a mayor según la opinión de los profesionales de las relaciones públicas del Reino Unido (UK PR Industry, 2020).

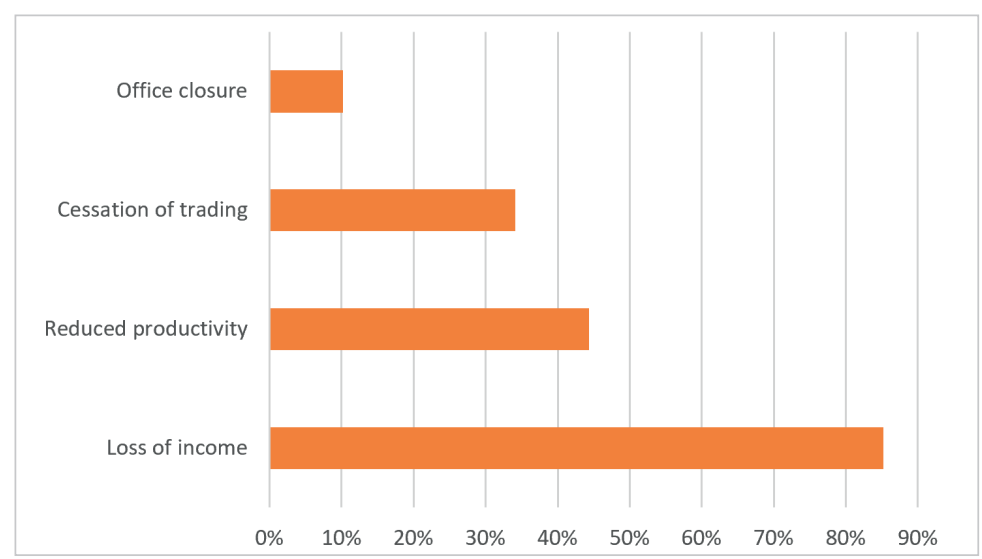

Figura 7. Medidas de contingencia a medio plazo que deben tomar las empresas para afrontar la crisis, priorizadas de menor a mayor según la opinión de los profesionales de las relaciones públicas del Reino Unido (UK PR Industry, 2020).

\section{La nueva responsabilidad social corporativa (RSC)}

Aunque suelen considerarse dos áreas de especialización distintas de las relaciones públicas (Xifra, 2017), hemos constatado anteriormente que una de las particularidades de la crisis del Covid-19 es que ha convertido la comunicación interna en un activo de la gestión de la RSC. Esta última es un factor clave en la reputación. Los rankings más conocidos de evaluación de la reputación, como el Global RepTrak del Reputation Institute, el Corporate Excellence-Centre for Reputation Leadership y el Monitor Empresarial de Reputación Corporativa (Merco) de Villafañe y Asociados tienen en cuenta que el comportamiento responsable y ético de las empresas a la hora de medir su reputación corporativa (FerruzGonzález, 2018).

Las empresas que se perciben como socialmente responsables cuentan con mayor apoyo por parte del público, lo que se traduce en comportamientos positivos hacia ellas, bien sea a través de la compra de sus productos o servicios, de la recomendación, del interés por trabajar en ellas, del interés por invertir, etc. (Carreras; Alloza; Carreras, 2013). Consecuentemente, la RSC puede ayudar a las empresas a navegar en tiempos muy inciertos, como las condiciones socioeconómicas impuestas por la pandemia del Covid-19. No hay espacio para el pensamiento individualista; la salud de uno está determinada por la salud del otro, por lo que, si no se aplica ahora la idea de ser responsables socialmente, difícilmente se aplicará en otras ocasiones.

El informe de Edelman (2020) muestra cuáles son los principios de una gestión eficaz de la RSC durante la pandemia del Covid-19, según los públicos de las organizaciones. El principal es el de centrase en soluciones antes que en ventas de productos y servicios. Hemos visto cómo marcas como Seat o Zara han modificado sus procesos productivos para fabricar respiradores artificiales y máscaras protectoras. Y lo han sabido comunicar, pues de eso se trata, de hacer saber que se han convertido en colaboradores necesarios de las administraciones públicas en la solución a la pandemia. Según los encuestados por Edelman (2020), el que una marca pase a producir productos que ayuden a las personas a enfrentar los desafíos, es un motivo de mantenimiento y mejora de la reputación para el $44 \%$, mientras que aquellos que, sabedores de que no es su obligación, esperan que lo hagan es del $45 \%$. Los mismos porcentajes se dan cuando se trata de ofrecer productos gratuitos o a precio asequible para el personal sanitario, personas de alto riesgo y aquellos cuyos trabajos se han visto afectados por la crisis. 
Otro principio que aglutina a un $85 \%$ de quienes participaron en la encuesta de Edelman (2020) es de utilizar el poder de la marca para comunicar información sanitaria veraz. No se trata de que las grandes marcas se dediquen a informar sobre el Covid-19 sino a que aquellas empresas que pueden hacerlo lo hagan y a unos públicos concretos. Antes hemos señalado la incapacidad de las universidades españolas para aprovechar el capital intelectual e informar a sus públicos internos sobre los avances en la investigación o la negación de fake news. Pero esta función podría estar destinada también a los públicos externos a través de la empresa privada. Son muchos los proyectos de investigación en el ámbito de la sanidad que implican la colaboración entre las universidades y el sector privado, por lo que las empresas que en ellos colaboran podrían pensar en convertirse en fuentes de información sanitaria privilegiada. Esta crisis ha puesto de manifiesto una cierta sobrexposición a información negativa muy poco favorable a la salud mental de una opinión pública confinada, así como una escasa o nula información de servicio público. Pensemos en el caso del uso de las mascarillas: nadie ha informado claramente sobre quién debe usarlas y cómo, cuándo y dónde utilizarlas para que realmente nos protejan o protejan a terceros. Si el tiempo de televisión dedicado a mostrar los aplausos de la gente a los sanitarios se hubiese invertido también en información de servicio público desde fuentes autorizadas (que no quiere decir públicas), la efectividad en términos de comportamiento saludable sería mucho mayor.

\section{En tiempos del Covid-19 no hay que co- municar de cualquier manera. Las orga- nizaciones y las marcas deben comuni- car con emoción, con compasión y con hechos}

Llegados a este punto, es muy importante insistir en lo que decíamos unas líneas más arriba: no es suficiente con ser socialmente responsable, hay que hacerlo saber. Esta es la esencia de la comunicación estratégica. En tiempos del Covid-19 no hay que comunicar de cualquier manera. Las organizaciones y las marcas deben comunicar con emoción, con compasión y con hechos. En el primer mes del confinamiento decretado por el gobierno hemos visto como las marcas han repensado rápidamente las líneas argumentales de sus campañas publicitarias. No obstante, los mensajes siguen siendo de esperanza, de que ya queda menos y cuando vuelva la normalidad las marcas ahí estarán, acompañándonos (curioso concepto de compañía) de nuevo. Aunque demostrar que te importa la situación de los afectados es un elemento positivo, no es fundamental, como evidencia el resultado del informe de Edelman (2020) a la cuestión de las declaraciones públicas que expresen empatía y apoyo a los más afectados por la pandemia por parte de las empresas. Solo el $34 \%$ de los encuestados considera que este hecho hará que estas marcas aumenten o mantengan su reputación.

El mismo informe muestra que dos principios críticos en la gestión de la RSC en tiempos como el del Covid-19 son centrar los mensajes en soluciones, lo que incluye, si es posible, focalizar cualquier publicidad en cómo los productos y servicios pueden ayudar a las personas a hacer frente a los desafíos de la vida relacionados con la pandemia, y hablar de los productos y servicios de manera que demuestren que se es consciente de la crisis y del impacto que está teniendo en la vida de las personas.

Hay marcas españolas que han seguido estos principios, y no han tenido ningún reparo en anunciar contagios de sus trabajadores. La compañía catalana Puig envió a ocho empleados a casa porque habían estado en contacto con una persona que dio positivo en Covid-19, hasta que se les hicieran los tests para saber si habían contraído el virus. Además, Puig creó un comité especial para evaluar y decidir las medidas a tomar y puso geles en las oficinas a disposición de toda la plantilla. O Telefónica, que fue la primera compañía española de renombre que comunicó un caso de coronavirus. Su decisión fue aislar también a los compañeros del afectado, para que teletrabajaran desde casa y vieran cómo evolucionaban sus síntomas. Igualmente, Telefónica mantuvo informados a sus trabajadores de las medidas de prevención que recomendaban desde la dirección a través de boletines internos.

En contraste, ha habido casos flagrantes que han afectado a clientes y consumidores, como los denunciados por el periódico digital Moncloa, quien en su edición de 13 de marzo de 2020 titulaba:

"Ryanair y Vueling se esconden tras un 902 que sangra a los angustiados por coronavirus". https://www.moncloa.com/ryanair-vueling-902-coronavirus

Pero se han dado situaciones más sibilinas, donde detrás de una solución se esconde una venta. O donde se venden soluciones que, en el fondo, son una carga financiera para el público. El sector bancario es el ejemplo más significativo de esto. Así, en el dossier de prensa que envió Bankinter a los medios el 7 de abril de 2020, se puede leer:

"Bankinter pone en marcha a partir de hoy una nueva campaña publicitaria que, con un discurso emotivo que busca empatizar con el público en el contexto actual, tiene como objetivo presentar las diferentes medidas habilitadas por el banco para mitigar el impacto generado por el COVID-19 entre sus clientes, así como poner en valor la fortaleza, solvencia y solidez de la entidad en este momento de crisis" https://saladecomunicacion.bankinter.com/prensa/bankinter-lanza-una-emotiva-campana-publicitaria-parapresentar-las-medidas-concretas-del-banco-en-el-momento-actual

Es decir, se ajusta a los principios y directrices que hemos visto al tratar de la comunicación interna: emotividad, empatía y soluciones. Ahora bien, entre estas soluciones siguen vendiéndose préstamos al $5 \%$ de interés TAE. Hay soluciones, pero siempre se aprovecha la ocasión para vender un producto. 
No obstante, en la nueva economía la línea que separa dar soluciones con vender es a menudo muy fina. Pensemos en el sector del ocio familiar y en el caso de Amazon, que ha ofrecido tres meses gratis de suscripción a Amazon Prime durante el confinamiento. Se trata de una solución y al mismo tiempo es un anzuelo comercial para el futuro. Pero hoy en día es una solución.

\section{Portavoces y medios de comunicación: el concepto de "medio refugio"}

Las crisis sanitarias requieren de portavoces fiables. Esto está siendo fundamental en la comunicación pública y gubernamental como se ha visto en las primeras semanas de la pandemia. El estudio de Edelman (2020) también ha analizado este extremo, con resultados significativos. Así, los portavoces más fiables son los científicos, las autoridades sanitarias y los médicos. En concreto, se consideran portavoces creíbles en asuntos relacionados con el virus y la respuesta de la marca: médico o autoridad científica (78\%), experto de la organización (48\%), líder corporativo de la organización (45\%), un afectado (44\%), fundador de la marca (43\%), empleado de la organización (34\%), influencers (30\%) y celebridades (26\%). Esto demuestra que es el momento de las relaciones públicas y de la gestión del riesgo reputacional, más que de la publicidad, ya que se han invertido los niveles de influencia de los portavoces que imperan en la publicidad, donde la legitimidad del mensaje es proporcional a la celebridad del portavoz (Kamins et al., 2013).

Los medios de comunicación preferidos para que las marcas comuniquen sobre el virus y su respuesta a la pandemia son los siguientes: medios tradicionales (TV, radio, prensa escrita) (45\%), correo electrónico (42\%), sitio web de la organización o marca (32\%), Facebook (31\%), Instagram (21\%), Twitter (19\%), sms (18\%), videos en streaming (17\%), correo ordinario (11\%). Estos datos se corroboran en relación con los earned media, es decir, con cualquier información que no sea generada por la organización o sus miembros, sino por métodos orgánicos a través de clientes, seguidores de las redes sociales, periodistas, blogueros u otros líderes de opinión (O’Neil; Eisenmann, 2017). En efecto, los resultados de Edelman (2020) en este punto son bastante elocuentes a la hora de considerar cuáles son los medios con un nivel de confianza más inmediato. Los porcentajes del grado de credibilidad (número de veces que necesitan ver la información repetida antes de creerla) de los earned media sobre información del Covid-19 también muestran que los medios tradicionales siguen siendo los que con uno o dos impactos mediáticos generan más credibilidad. Así lo considera el $46 \%$ de los encuestados respecto de los medios nacionales y locales, aunque el $18 \%$ (medios nacionales) y el $16 \%$ (medios locales) considera que su credibilidad se asume inmediatamente, solo con ofrecer la información.

Este dato es muy importante para entender que los medios tradicionales, en estas situaciones de crisis globales, actúan como medios refugio, siguiendo con el paralelismo del sistema mediático con el económico, que ya en su día analizamos a través de otro concepto importado de la economía, el de subsidios informativos (Xifra, 2001). Los medios refugio son aquellos que, como el oro o el dólar en el terreno económico, generan más confianza, porque su tradición es un atributo que refuerza la relación que tenemos con ellos, frente a unos nuevos medios de un sistema telemático y virtual que represen-

tan un campo propicio para las noticias falsas, los bulos y los rumores, pues la función de gatekeeping en estos medios no solo no es pacífica ni fácil, al chocar con derechos individuales y obstáculos técnicos. El tiempo de existencia de una relación entre una organización y su público ya fue en su día considerado un elemento clave para determinar la confianza en las relaciones entre organizaciones y públicos (Ledingham; Bruning, 1998).

Por este motivo, únicamente el $8 \%$ de la muestra del informe de Edelman (2020) considera que las redes sociales son confiables de por sí, sin necesidad de contrastar la información. Una cifra muy baja, pues la credibilidad de las redes sociales es, a pesar de todo y en términos generales, importante (Diezhandino, 2012), aunque también es cierto que, frente los medios tradicionales, su fiabilidad es escasa (Herrero-Curiel, 2015). Con todo, la idea de medio refugio se con- 
firma con la baja credibilidad que tienen los sitios web, las cuentas en redes sociales y la publicidad de la marca. Todas se sitúan entre un $50 \%$ y un $55 \%$ de credibilidad, pero ninguna de ellas supera el $15 \%$ a la hora de considerar que sus informaciones generan una confianza inmediata sin necesidad de repetirse o de contrastarse.

\section{Big data e inteligencia artificial: nuevos desafíos}

Tal y como han apuntado Martínez-Martínez y Larra-Navarra (2015), el impacto de los datos masivos (big data) en el campo de la comunicación se mide en términos cuantitativos y también cualitativos, subrayando los cambios que introducen en la forma de comprender la sociedad que permiten acercarnos a lo micro, ganar en percepción macro y descubrir tendencias, pautas y correlaciones que permiten hacer predicciones en sectores muy variados, entre ellos la salud. Por añadidura, Túñez et al. (2018), en su estudio sobre el rol de los algoritmos, los bots y la automatización en la elaboración de información, bajo el horizonte propuesto por Hansen et al., (2017), ponen de manifiesto que los receptores de información tienen derecho a entender cómo es usada la inteligencia artificial, y a que las decisiones se tomen sin tecnicismos, esto es, en términos comprensibles.

A pesar de que la elaboración automatizada de noticias es un campo relativamente nuevo, nos es de utilidad para nuestro propósito de la automatización de mensajes destinados a clientes en situaciones excepcionales. En efecto, la aplicación de algoritmos en los procesos comunicativos entre empresas y sus públicos, principalmente clientes, es una práctica muy institucionalizada en el comercio electrónico. Se trata de un proceso que se inició en la década de los 80 del siglo XX para culminar en la segunda década del presente siglo (Lindén, 2017).

El primer congreso online de la Asociación Nacional de Big Data y Analytics (Anban) reunió bajo el título Inteligencia artificial y big data contra la Covid-19 a múltiples iniciativas que utilizando técnicas de inteligencia artificial y de análisis de datos ayudan en la lucha frente a la pandemia del coronavirus. Desde geolocalización hasta mapas del tránsito, se presentaron durante la jornada varios proyectos que colaboran para contener el número de contagios y estimar la evolución de la enfermedad. En suma, la pandemia del Covid-19 está poniendo en evidencia que resulta esencial contar con datos para evitar los contagios y acabar con la misma, más allá de las soluciones epidemiológicas y serológicas.

En el campo de la comunicación corporativa y las relaciones públicas, la inteligencia artificial y los datos masivos (big data) han cambiado para siempre la forma en que se planifican las campañas, y en especial en cómo se fijan los objetivos, cómo se elaboran y dirigen los mensajes y en cómo se evalúa su efectividad. En una palabra, los big data se han convertido en estructurales. Y esto es muy cierto en las relaciones con diferentes públicos y especialmente con clientes y consumidores. En consecuencia, el ritmo acelerado del comercio, la digitalización de los medios, la necesidad de que las empresas entreguen más y mejores resultados ha modificado irreversiblemente el panorama de las relaciones públicas de un sector de relaciones a un negocio de terabytes (Gregory; Halff, 2020). Pero ambos deberían ser compatibles o, al menos, parecen serlo en tiempos de bonanza económica y sanitaria.

Ahora bien, la inteligencia artificial y sus extensiones no saben de emociones, al menos hoy en día. Hemos apuntado como la comunicación emocional es fundamental en situaciones críticas como la que nos ocupa. Desde esta perspectiva, es notable como algunas grandes marcas no han podido añadir el valor de la comunicación emocional en sus relaciones con diferentes públicos y únicamente han podido darle a la tecla que detiene los procesos comunicativos sobre los que se basa, en tiempos de bonanza, su comunicación con sus públicos. Hay casos paradigmáticos. El de Amazon es uno de los que más. De levantarnos cada mañana con unas recomendaciones de acuerdo con nuestros hábitos de compra, se ha pasado al silencio.

Logaritmos y emociones son realidades alejadas, contradictorias parece ser, por lo que aquellas compañías que basan la gestión de su comunicación en procesos de inteligencia artificial seguramente deberán articular planes de comunicación de riesgo para evitar convertirse en marcas caracterizadas por su artificiosidad y que no pueden llegar a cumplir con aquellos principios que hemos indicado tanto en el ejercicio de su comunicación interna, de su RSC como de su política de comunicación en general.

\section{Aprende a diferenciar los síntomas}

\begin{tabular}{|c|c|c|c|}
\hline Síntomas & COVID-19 & GRIPE & RESFRIADO \\
\hline Fiebre & $\bullet$ & $\bullet$ & \\
\hline Tos & $\bullet$ & $\bullet$ & $\bullet$ \\
\hline Moco & & $\bullet$ & \\
\hline Congestión Nasal & & & $\bullet$ \\
\hline Estornudos & & $\bullet$ & $\bullet$ \\
\hline Dolor de garganta & & & $\bullet$ \\
\hline Malestar en la garganta & & & $\bullet$ \\
\hline Dificultad para respirar & $\bullet$ & & \\
\hline Flema & (amarlllo verdosa) & & \\
\hline Vómito & & $\bullet$ & \\
\hline Diarrea & & $\bullet$ & \\
\hline Cansancio / Debilidad & $\bullet$ & & \\
\hline Quebrahueso & & $\bullet$ & \\
\hline x-ray pulmón mancha & $\bullet$ & & \\
\hline
\end{tabular}

Figura 9. Información falsa sobre los síntomas del Covid-19 que tuvo que ser rebatida por Cruz Roja Española.

https://eldesmarque.com/actualidad/off-topic/1383306-fake-newssobre-el-coronavirus-cruz-roja-sale-al-paso-de-una-tabla-de-sintomas 


\section{Reflexiones finales a modo de conclusión abierta}

No es fácil abordar el tema de los efectos que una pandemia como el Covid-19 puede tener sobre la comunicación corporativa y las relaciones públicas cuando estamos todavía en el ojo del huracán, pues no nos permite calibrar eficazmente sus daños. Con todo, los estudios realizados a finales de marzo y principios de abril de 2020 y la experiencia directa nos han permitido presentar algunas reflexiones y pautas sobre cómo gestionar la comunicación y el riesgo reputacional en estas situaciones.

Hay dos datos muy relevantes del informe de Edelman (2020) que nos ha acompañado en este artículo, con los que se puede resumir todo lo dicho en él. El primero es que el $65 \%$ de los encuestados está de acuerdo en que en este momento de crisis recurre a las marcas en las que tiene la certeza de que puede confiar, pero el $71 \%$ está de acuerdo en que las marcas y compañías que priorizan sus ganancias sobre las personas durante esta crisis perderán su confianza para siempre. Estos dos datos reflejan a la perfección la tensión que define el momento de gestión de la incertidumbre sanitaria y empresarial y del riesgo reputacional que se ha vivido con la aparición y propagación global de la pandemia del Covid-19.

En las líneas precedentes hemos combinado los resultados de las primerizas investigaciones llevadas a cabo en el terreno profesional de la comunicación corporativa con reflexiones y sugerencias sobre lo que habría que hacer y dejar de hacer en estas situaciones. Aun así, tenemos la sensación de que hay marcas que saben desaparecer del mapa de la crisis, evitando así una exposición pública arriesgada (de hecho, es notorio que la inversión publicitaria descendió notablemente durante los primeros meses de la pandemia). Son marcas que no han hecho valer aquel principio con el que Schmertz y Novak (1987) titularon su celebrado libro sobre relaciones con la prensa: el silencio no es renLas crisis se resuelven recobrando y restableciendo la confianza table. Este principio ha adquirido otra dimensión en las semanas iniciales de una pandemia como la que nos ocupa. No es que haya pasado de ser prácticamente una norma de las relaciones con la prensa a ser un principio general de la comunicación estratégica, sino que ha sido el concepto mismo de silencio el que ha cambiado. No se trata únicamente de no decir nada, ya que este es un error estratégico global, no propio de ninguna especialidad de la comunicación corporativa. Se trata de decir aquello que los públicos de la organización esperan que se diga porque esa información les va a rebajar el estado de preocupación por los efectos que la crisis tiene en su vida cotidiana.

Si una lección de comunicación corporativa y relaciones públicas hay que sacar de la pandemia que nos ocupa es que, en estos tiempos de crisis global con ramificaciones locales de naturaleza distinta a la sanitaria, aquellas organizaciones que en tiempos de normalidad son visibles, deben seguir siéndolo, pero para poner de su parte, para ayudar a encontrar soluciones, sanitarias y comunicativas, que respondan a lo que sus públicos y la sociedad les exige. No es el momento de desaparecer, sino de mostrar y utilizar todos los recursos y creatividad a su alcance para marcar la diferencia. Y si no se tiene acceso a estos recursos, explicar claramente los motivos.

Las relaciones públicas no son un conjunto de técnicas de marketing, sino que constituyen las raíces sociales de una economía de mercado. Entre sus funciones está la de crear los fundamentos para una economía fuerte y sólida que resista lo máximo ante una crisis. Una economía en la que la confianza juega un papel fundamental, como demuestra el hecho de que cada vez que nos afecta una crisis importante, se invoca a la confianza, hablando de crisis de confianza en los mercados, en los estados, en la sanidad, en la Unión Europea, en el futuro. Por tanto, las crisis se resuelven recobrando y restableciendo la confianza (Laurent, 2109).

En el ámbito corporativo esta confianza, para que no se pierda, requiere de ciertos comportamientos empresariales alejados de los procesos de comercialización, y propios de la gestión de una comunicación clara, directa y rápida, que evite cualquier distorsión del lenguaje. El mapa conceptual del Covid-19 es muy amplio e incluye un lenguaje que queriendo ser claro a menudo puede esconder un significado que, en el inconsciente colectivo puede generar conflictos sociales. Sin ir más lejos, el Behavioral Insights Research Center (2020), en su informe "Using social and behavioural science to support COVID-19 pandemic response" alerta del peligro del uso de la expresión "distanciamiento social" como remedio sine qua non a los contagios, que puede inducir a cortar interacciones necesarias, siendo preferible la expresión "distanciamiento físico" porque no deshabilita la conexión social, posible incluso cuando las personas están físicamente separadas.

La cuestión del lenguaje será un tema de investigación futura, necesario para saber utilizar un vocabulario riguroso y eficaz que, aunque esté promovido por las autoridades sanitarias, las empresas incor-

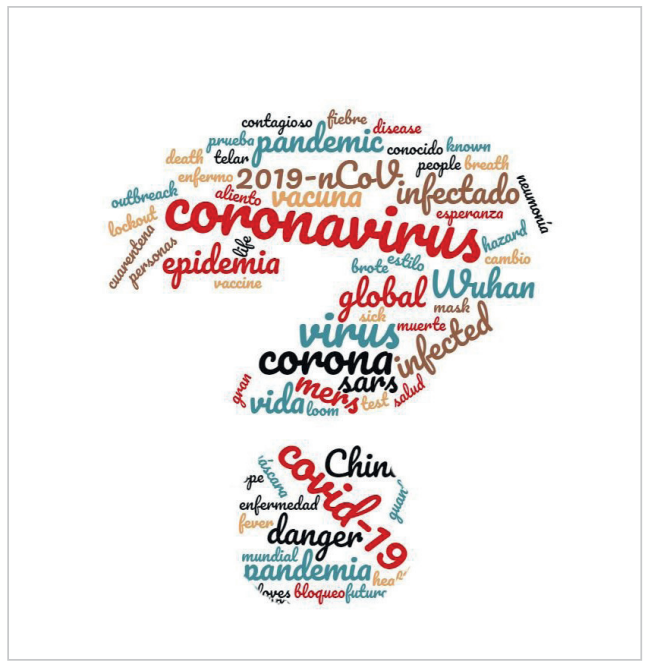

Figura 10. Mapa conceptual del coronavirus. Realizado con https://www.nubedepalabras.es 
poren a sus mensajes. De la misma manera que hemos sido muy cuidadosos en el uso del lenguaje en determinados campos, tendremos que acostumbrarnos a saber distinguir entre una pandemia y una guerra. Esta referencia a la guerra no está justificada desde un punto de vista histórico porque no hay enemigos identificables ni muertes violentas. No hay guerra, sino un tiempo de guerra.

Llegados a este punto final, ¿qué nos deparará esta crisis para el futuro de nuestra investigación? Una vez se haya controlado la crisis del Covid-19, los investigadores en comunicación corporativa deberán priorizar sus investigaciones en cómo han actuado las organizaciones implicadas en la crisis y cómo su actuación ha afectado a su reputación. El trabajo pionero de Woods (2016), citado al principio de este artículo, puede ser una guía, pero no un modelo, pues las circunstancias fueron distintas y el modelo sanitario estadounidense es radicalmente distinto del nuestro. Pero si algo está claro es que esta situación de pandemia global en tiempos de hiperinformación ha abierto un escenario donde los actores y los procesos de comunicación corporativa requieren de nuevos lubricantes que permitan que la comunicación tenga un efecto balsámico que ayude a solucionar los problemas derivados de aquellas crisis colaterales, la económica y social. Quizá ha llegado el momento de dar la razón, o una parte de ésta, a aquellos que consideran la gestión de la incertidumbre un elemento estructural de la comunicación organizacional y las relaciones públicas. Investigaciones futuras deberían explotar esta línea, más rica epistemológicamente hablando.

Una vez se haya controlado la crisis del Covid-19, los investigadores en comunicación corporativa deberán priorizar sus investigaciones en cómo han actuado las organizaciones implicadas en la crisis y cómo su actuación ha afectado a su reputación

\section{Referencias}

Arthur W. Page Society (2017). "The CEO view: communications at the center of the enterprise". https://page.org/thought-leadership/the-ceo-view-communications-at-the-center-of-the-enterprise

Behavioral Insights Research Center (2020). "Using social and behavioural science to support COVID-19 pandemic response".

https://instituteforpr.org/behavioral-insights-research-center/about-birc

Blumer, Harold (1946). "Collective behavior". In: Lee, Algred McCung (ed.). New outlines of the principle of sociology. New York: Barnes \& Noble. ISBN: 9780064600262

Carreras, Enrique; Alloza, Ángel; Carreras, Ana (2013). Reputación corporativa. Madrid: LID Editorial. ISBN: 97884 83567210

Coombs, W. Timothy (1995). "Choosing the right words: The development of guidelines for the selection of the 'appropriate' crisis-response strategies". Management communication quarterly, v. 8, n. 4, pp. 447-476.

https://doi.org/10.1177/0893318995008004003

Coombs, W. Timothy (1998). "An analytic framework for crisis situations: Better responses from a better understanding of the situation". Journal of public relations research, v. 10, n. 3, pp. 177-191.

https://doi.org/10.1207/s1532754xjprr1003_02

Coombs, W. Timothy (2006). "The prospective power of crisis response strategies: Managing reputational assets during a crisis". Journal of promotion management, v. 12, n. 3-4, pp. 241-260.

https://doi.org/10.1300/J057v12n03_13

Coombs, W. Timothy (2012). Ongoing crisis communication: Planning, managing, and responding, $3^{\text {rd }}$ ed. Thousand Oaks: SAGE Publications. ISBN: 9781412983105

Corporate Excellence; IE Business School (2016). "Informe de tendencias en gestión de intangibles".

https://www.corporateexcellence.org/recurso/approaching-the-future-informe-de-tendencias-en/e3b17de7-818c435c-8c7a-089ad8f2eaf3

Cuenca, Joan; Verazzi, Laura (2018) Guía fundamental de la comunicación interna. Barcelona: Editorial UOC. ISBN: 978 8491802723

Dewey, John (2004). La opinión pública y sus problemas. Madrid: Ediciones Morata. ISBN: 9788471124883

Diezhandino, María-Pilar (2012). El periodista en la encrucijada. Barcelona: Fundación Telefónica. ISBN: 9788408008248

Edelman (2019). "Trust barometer global report".

https://www.edelman.com/sites/g/files/aatuss191/files/2019-02/2019_Edelman_Trust_Barometer_Global_Report_2.pdf

Edelman (2020). "Brand trust and the coronavirus pandemic".

https://www.edelman.com/research/covid-19-brand-trust-report 
Edwards, Lee (2006). "Rethinking power in public relations". Public relations review, v. 32, n. 3, pp. $229-231$. https://doi.org/10.1016/j.pubrev.2006.05.013

Edwards, Lee (2014). Power, diversity and public relations, Londres: Routledge. ISBN: 9780415811958

Ferruz-González, Sonia-Aránzazu (2018). Reputación corporativa. Estudio del concepto y las metodologías para su medición: propuesta de un concepto y metodología de consenso. Tesis doctoral. Madrid: Universidad Complutense de Madrid. https://eprints.ucm.es/47772

Fombrun, Charles J.; Gardberg, Naomi A.; Sever, Joy M. (2000). "The reputation quotient: A multi-stakeholder measure of corporate reputation". Journal of brand management, v. 7, n. 4, pp. 241-255.

https://doi.org/10.1057/bm.2000.10

Fombrun, Charles. J.; Ponzi, Leonard J.; Newburry, William (2015). "Stakeholder tracking and analysis: The RepTrak system for measuring corporate reputation". Corporate reputation review, v. 18, n. 1, pp. 3-24.

https://doi.org/10.1057/crr.2014.21

Fombrun, Charles. J.; Shanley, Mark (1990). "What's in a name? Reputation building and corporate strategy". Academy of Management journal, v. 33, n. 2, pp. 233-258.

https://doi.org/ 10.2307/256324

Grunig, James E. (1976). Communication behaviors occurring in decision and non-decision situations. Journalism quarterly, v. 53, pp. 252-286.

https://doi.org/10.1177/107769907605300209

Grunig, James E. (1983). Communication behaviors and attitudes of environmental publics: Two studies. Journalism monographs, v. 81

Grunig, James E.; Hunt, Todd (1984). Managing public relations, Fort Worth, NJ: Rinehart and Wilson. ISBN: 9780 030583377

Grunig, James E.; Repper, Fred C. (1992). "Strategic management, publics, and issues". In: J. E. Grunig, James E. (ed.). Excellence in public relations and communication management, Hillsdale, NJ: Lawrence Erlbaum. ISBN: 9780805802276

Hamori, Monika (2003). "The impact of reputation capital on the career paths of departing employees". Journal of inteIlectual capital, v. 4, n. 3, pp. 304-315. https://doi.org/10.1108/14691930310487770

Hansen, Mark; Roca-Sales, Meritxell; Keegan, Jonathan M.; King, George (2017). Artificial untelligence: Practice and implications for journalism. Columbia University Libraries; Tow Center for Digital Journalism. https://doi.org/10.7916/D8X92PRD

Herrero-Curiel, Eva (2015). “La credibilidad de las redes sociales en el ámbito periodístico". Transinformação, v. 27, n. 2, pp. 165-171.

https://doi.org/10.1590/0103-37862015000200006

Hutton, James G.; Goodman, Michael B.; Alexander, Jill B.; Genest, Christina M. (2001). “Reputation management: the new face of corporate public relations?". Public relations review, v. 27, n. 3, pp. 247-261. https://doi.org/10.1016/S0363-8111(01)00085-6

Kamins; Michael A.; Brand, Meribeth J.; Hoeke, Stuart A.; Moe, John C. (2013). "Two-sided versus one-sided celebrity endorsements: The impact on advertising effectiveness and credibility". Journal of advertising, v. 18, n. 1, pp. 4-10. https://doi.org/10.1080/00913367.1989.10673146

Kim, Heevon; Pilny, Aandrew (2019). "The use of enterprise social media and its disparate effects on the social connectivity of globally dispersed workers". International journal of business communication, pp. 1-19.

https://doi.org/10.1177/2329488419877233

Laurent, Éloi (2019). Économie de la confiance. Paris: La Découverte. ISBN: 9782348043550

Ledingham, John A.; Bruning, Stephen D. (1998). "Relationship management in public relations: dimensions of an organization-public relationship". Public relations review, v. 24, n. 1, pp. 55-65. https://doi.org/10.1016/S0363-8111(98)80020-9

Lee, Yeunjae; Li, Jo-Yun-Queenie (2020). “The value of internal communication in enhancing employees' health information disclosure intentions in the workplace". Public relations review, v. 46, n. 1.

https://doi.org/10.1016/j.pubrev.2019.101872

Lindén, Carl-Gustav (2017). "Algorithms for journalism: The future of news work". The journal of media innovations, v. 4, n. 1, pp. 60-76.

https://doi.org/10.5617/jmi.v4i1.2420 
Luc Beauregard Centre of Excellence in Communications Research (2017) "The CEO Communication Audit". https://www.concordia.ca/content/dam/jmsb/docs/research-centres/luc-beauregard/CEO-Summit-report.pdf

Martínez-Martínez, Silvia; Lara-Navarra, Pablo (2015). "El big data transforma la interpretación de los medios sociales". El profesional de la información, v. 23, n. 6, pp. 575-581.

https://doi.org/10.3145/epi.2014.nov.03

Mazmanian, Melissa (2013). "Avoiding the trap of constant connectivity: When congruent frames allow for heterogeneous practices". Academy of Management journal, v. 56, pp. 1225-1250.

https://doi.org/10.5465/amj.2010.0787

McKie, David; Lawniczak, Ryszard (2009). "Economics and public relations in a time of downturn: Dismal science, unseen history, and the need for dialogue". Public relations review, v. 35, n. 4, pp. 335-339.

https://doi.org/10.1016/j.pubrev.2009.08.008

Men, Linjuan-Rita (2014). "Internal reputation management: the impact of authentic leadership and transparent communication". Corporate reputation review, v. 17, n. 4, pp. 254-272.

https://doi.org/10.1057/crr.2014.14

Men, Linjuan-Rita; Yue, Cen-April (2019). “Creating a positive emotional culture: Effect of internal communication and impact on employee supportive behaviors". Public relations review, v. 45, n. 2.

https://doi.org/10.1016/j.pubrev.2019.03.001

Miquel-Segarra, Susana; Aced-Toledano, Cristina (2019). "Objectives and difficulties in the evaluation of internal communication in Spanish companies". El profesional de la información, v. 28, n. 5, e280521.

https://doi.org/10.3145/epi.2019.sep.21

O’Neil, Julie; Eisenmann, Marianne (2017). “An examination of how source classification impacts credibility and consumer behavior". Public relations review, v. 43, n. 2, pp. 278-292.

https://doi.org/10.1016/j.pubrev.2017.02.011

O’Neil, Julie; Ewing, Michele; Smith, Stacey; Williams, Sean (2018) "A Delphi study to identify standards for internal communication". Public relations journal, v. 11, n. 3.

https://prjournal.instituteforpr.org/wp-content/uploads/1.-A-Delphi-Study-to-Identify-Standards-for-IC-.pdf

Orangefiery (2020). "Leadership communications during COVID-19: A survey of U.S. organizations".

https://orangefiery.com/2020/04/03/leadership-communications-during-covid-19-survey

Roberts, Peter W.; Dowling, Grahame R. (2002). "Corporate reputation and sustained superior financial performance". Strategic management journal, v. 23, n. 12, pp. 1077-1093.

https://doi.org/10.1002/smj.274

Schaarschmidt, Mario; Walsh, Gianfranco; Ivens, Stefan (2015). "Perceived external reputation as a driver of organizational citizenship behavior: Replication and extension". Corporate reputation review, v. 18, n. 4, pp. 314-336.

https://doi.org/10.1057/crr.2015.19

Schmertz, Herb; Novak, William (1987). El silencio no es rentable. Barcelona: Planeta. ISBN: 9788432078873

Sotillo, Sandra (2017). La gestión profesional de la reputación del CEO como elemento generador de valor para las organizaciones. Tesis doctoral. Castellón: Universitat Jaume I.

https://www.tdx.cat/handle/10803/405335\#page=1

Ter Hoeven, Claartje L.; Van Zoonen, Ward (2020). "Helping others and feeling engaged in the context of workplace flexibility: The importance of communication control". International journal of business communication, v. 57, n. 3, pp. 1-22. https://doi.org/10.1177/2329488419898799

Túñez-López, José-Miguel; Toural-Bran, Carlos; Cacheiro-Requeijo, Santiago (2018). "Uso de bots y algoritmos para automatizar la redacción de noticias: percepción y actitudes de los periodistas en España”. El profesional de la información, v. 27 , n. 4 , pp. $750-758$.

https://doi.org/10.3145/epi.2018.jul.04

UK PR Industry (2020). "\#FuturePRoof survey reveals drastic impact of COVID-19 on UK PR industry". https://www.futureproofingcomms.co.uk/thelatest/2020/3/22/futureproof-survey-reveals-drastic-impact-of-covid-19on-uk-pr-industry

Wæraas, Arild; Dahle, Dag-Yngve (2019). "When reputation management is people management: Implications for employee voice”. European management journal, v. 38, n. 2, pp. 277-287.

https://doi.org/10.1016/j.emj.2019.08.010 
Weber Shandwick (2012), "The company behind the brand: In reputation we trust - CEO spotlight". https://www.webershandwick.com/wp-content/uploads/2018/04/CEO_Spotlight_ExecSummary.pdf

Weigelt, Keith; Camerer, Colin (1988). "Reputation and corporate strategy: A review of recent theory". Strategic management journal, v, 9, n. 5, pp. 443-455. https://doi.org/10.1002/smj.4250090505

Woods, Chelsea L. (2016). "When more than reputation is at risk: How two hospitals responded to Ebola". Public relations review, v. 42, n. 5, pp. 893-902.

https://doi.org/10.1016/j.pubrev.2016.10.002

Xifra, Jordi (2011). "Subsidios informativos y función documental de las salas de prensa online de los ministerios españoles". El profesional de la información, v. 20, n. 3, pp. 270-275.

https://doi.org/10.3145/epi.2011.may.04

Xifra, Jordi (2017). Manual de relaciones públicas e institucionales (3a ed.). Madrid: Tecnos. ISBN: 9788430972135

Xifra, Jordi; Ordeix, Enric (2009). "Managing reputational risk in an economic downturn: The case of Banco Santander". Public relations review, v. 35, n. 4, pp. 353-360.

https://doi.org/10.1016/j.pubrev.2009.08.004

Yoon, Eunsang; Guffey, Hugh J.; Kijewski, Valerie (1993). "The effects of information and company reputation on intentions to buy a business service". Journal of business research, v. 27, n. 3, pp. 215-228.

https://doi.org/10.1016/0148-2963(93)90027-M

Yue, Cen-April; Men, Linjuan-Rita; Ferguson, Mary-Ann (2019). “Bridging transformational leadership, transparent communication, and employee openness to change: The mediating role of trust". Public relations review, v. 45 , n. 3. https://doi.org/10.1016/j.pubrev.2019.04.012

Zerfass, Ansgar; Tench, Ralph; Verhoeven, Piet; Verčič, Dejan; Moreno, Ángeles (2018). European communication monitor 2018. Strategic communication and the challenges of fake news, trust, leadership, work, stress and job satisfaction. Bruselas: EACD/Euprera, Quadriga Media.

http://www.communicationmonitor.eu/2018/06/13/ecm-european-communication-monitor-2018

https://www.rediris.es/list/info/iwetel.html bibliotecas y documenta ción
Con unos 6.000 miembros, IweTel es la mayor lista de distribución en castellano para debatir y estar al
día sobre temas de biblioteconomía y documentación.
Fue creada en 1993 por Tomàs Baiget, como complemento de Information World en Español (IWE), revista
que en 1999 pasó a denominarse El profesional de la información (EPI).
Desde 1998 IweTel está alojada en el servicio de listas de RedIRIS, siendo posible consultar en sus archi-
vos estos 18 años de la historia de la documentación en España:
https://listserv.rediris.es/cgi-bin/wa?AO=IWETEL
La lista cuenta con 4 moderadores que permanentemente filtran los mensajes para evitar spam, men-
sajes inapropiados, anuncios, mensajes repetidos, etc.:
David Gómez (Observatorio de la Infancia de Andalucía),
Isabel Olea (EPI, León),
Julio Alonso-Arévalo (Universidad de Salamanca),
Tomàs Baiget (EPI, Barcelona).
https://listserv.rediris.es/cgi-bin/wa?SUBED1=IWETEL\&A=1

